\title{
Laboreal
}

Volume $16 \mathrm{~N}^{\circ} 1 \mid 2020$

Quando o trabalho real é tabu

\section{8 de fevereiro de 2002 : os acórdãos 'amianto' do Supremo Tribunal de Justiça da França redefinem a falta indesculpável do empregador}

28 de febrero de 2002 : las sentencias "amianto" del Tribunal Supremo de Justicia de Francia redefinen la falta inexcusable del empleador

28 février 2002: les arrêts " amiante »: la cour de Cassation française re-définit la faute inexcusable de l'employeur

February 28, 2002: the 'asbestos' decisions of the French Supreme Court redefine the inexcusable fault of the employer

\section{Annie Thébaud-Mony}

Tradutor. Teresa Lello e Christiano Lello

\section{(2) OpenEdition}

\section{Journals}

Edição electrónica

URL: http://journals.openedition.org/laboreal/16208

DOI: $10.4000 /$ laboreal.16208

ISSN: 1646-5237

Editora

Universidade do Porto

\section{Refêrencia eletrónica}

Annie Thébaud-Mony, " 28 de fevereiro de 2002 : os acórdãos 'amianto' do Supremo Tribunal de Justiça da França redefinem a falta indesculpável do empregador », Laboreal [Online], Volume $16 \mathrm{~N}^{0} 1$ । 2020, posto online no dia 01 julho 2020, consultado o 19 setembro 2020. URL : http:// journals.openedition.org/laboreal/16208; DOI : https://doi.org/10.4000/laboreal.16208

\section{Este documento foi criado de forma automática no dia 19 setembro 2020.}

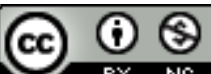

Laboreal está licenciado com uma Licença Creative Commons - Atribuição-NãoComercial 4.0 Internacional. 


\section{8 de fevereiro de 2002 : os acórdãos 'amianto' do Supremo Tribunal de Justiça da França redefinem a falta indesculpável do empregador}

28 de febrero de 2002 : las sentencias "amianto" del Tribunal Supremo de Justicia de Francia redefinen la falta inexcusable del empleador

28 février 2002: les arrêts " amiante »: la cour de Cassation française re-définit la faute inexcusable de l'employeur

February 28, 2002: the 'asbestos' decisions of the French Supreme Court redefine the inexcusable fault of the employer

Annie Thébaud-Mony

Tradução : Teresa Lello e Christiano Lello

\section{NOTA DO EDITOR}

Tradução [1] : Teresa Lello e Christiano Lello - tlello12@gmail.com

1 O movimento social das vítimas do amianto em França passou por duas fases de mobilização determinantes para o reconhecimento social e político da catástrofe sanitária causada por essas fibras minerais.

2 A primeira fase ocorreu na década de 1970, quando cientistas que trabalhavam nos laboratórios do campus universitário de Jussieu em Paris, apercebendo-se da extensão da contaminação causada pelo amianto flocado existente nos edifícios, iniciaram uma luta pela sua segurança. Simultaneamente, levaram a cabo um trabalho de informação no intuito de apoiar a mobilização dos trabalhadores das fábricas de amianto, e reuniram numa obra bem documentada todos os conhecimentos então existentes sobre 
os perigos mortais que essa fibra representa (Collectif intersyndical Sécurité des Universités Jussieu, 1977).

3 Na altura, foram tomadas duas medidas políticas : a inclusão do mesotelioma (cancro da pleura típico da exposição ao amianto) na tabela $\mathrm{n}^{0} 30$ das doenças profissionais causadas pelo amianto e a aprovação do decreto de 17 de agosto de 1977 que estabelecia um valor limite de exposição (VLE), já então considerado desadequado. Na verdade, o relatório de uma reunião de especialistas em questões relacionadas com o amianto do Secretariado Internacional do Trabalho (BIT), realizada em dezembro de 1973, já referia que o VLE de $2 \mathrm{f} / \mathrm{cm} 3$ devia ser considerado um "objetivo provisório" de prevenção dos riscos, dado "aplicar-se aos efeitos fibrogénicos do amianto e não aos efeitos carcinogénicos, relativamente aos quais não existe atualmente nenhum valor" (BIT, 1973).

4 A segunda fase de mobilização, que vai de 1994 à primeira década de 2000, foi a da luta pela proibição do amianto em França, pela adoção de medidas de segurança na gestão do amianto já aplicado e pela melhoria das condições de indemnização das vítimas, a começar pelos trabalhadores. A proibição foi conseguida em julho de 1996, com efeitos a partir de 1 de janeiro de 1997. Criaram-se, então, diversas associações e comissões locais que tinham como prioridade a luta pelo reconhecimento dos danos causados às vítimas. O objetivo das várias forças envolvidas nesta luta (associações de vítimas, cientistas, advogados, médicos, agentes de prevenção) era obter justiça para as vítimas. Em França, o amianto causou mais de 3000 mortes por ano desde a década de 1990, o que ainda se mantém atualmente.

5 Esses acórdãos representam uma das maiores vitórias judiciais conseguidas pela mobilização social para o reconhecimento dos danos sofridos pelas vítimas do amianto, sendo que o seu âmbito abrange não só as indemnizações, mas também a prevenção.

\section{Um princípio de justiça : reconhecer a falta indesculpável do empregador}

6 Até às ações movidas pelas vítimas do amianto na década de 1990, e segundo uma jurisprudência antiga $\left[{ }^{2}\right]$, depois de ter lhe sido reconhecida uma doença profissional, a vítima podia alegar "falta indesculpável do empregador" desde que apresentasse provas de que uma falta de "excecional gravidade" (designadamente, a violação dos regulamentos de segurança) estivera na origem do acidente de trabalho ou da doença profissional (AT/DP). Na prática- esse procedimento que teria permitido uma indemnização, digna desse nome, às vítimas de AT/DP- ou seja, semelhante à que a lei prevê no caso da chamada indemnização "integral", em direito civil - quase nunca era aplicado para as doenças profissionais.

7 Em tempos ainda mais recuados, um acórdão de 27 de novembro de 1884, "Jean Thommes", caído no esquecimento, tinha criado a "obrigação de segurança e de resultado". Esse acórdão reconhecia a culpa do patrão que não tivesse garantido a segurança do trabalhador, vindo o acidente provar a inexistência de um dispositivo de prevenção (Sargos, 2015). Surgirá, depois, uma lei cuja pedra angular vai ser essa obrigação. De facto, ao iniciar a legislação laboral em matéria de higiene e segurança, a lei de 12 de julho de 1893 refere a questão das poeiras, quando define a obrigação de segurança e de resultado: "o ar das oficinas será renovado de forma a permanecer no estado de pureza 
indispensável à saúde dos operários". Esta obrigação de segurança do dono da empresa figura ainda hoje no código do Direito do Trabalho [3]. A diretiva-quadro europeia de 1989 sobre a saúde dos trabalhadores, transposta para o direito francês [4], reforça ainda mais a atualidade dessa obrigação, sendo a entidade patronal obrigada a garantir a sua eficácia, o que permite, assim, considerar que uma violação desta regra constitui uma falta indesculpável do empregador.

8 No caso dos trabalhadores vítimas do amianto, a falta indesculpável do empregador surge aos olhos dos advogados e das associações como inteiramente legítima. Apoiados pelas associações, e igualmente por advogados e cientistas, os trabalhadores vítimas de doenças causadas pelo amianto, ou as suas famílias em caso de morte destes, apresentaram ao Tribunal dos Assuntos de Segurança Social (TASS), desde a década de 1990, várias dezenas de ações. Estamos a falar de antigos operários das fábricas ETERNIT (fibrocimento), AMISOL (têxteis com amianto), mas também dos que trabalharam para grandes utilizadores de amianto como a siderurgia (ASCOMETAL) e estaleiros navais. Evidentemente que os industriais recorriam e os processos acabaram por chegar ao Supremo, cuja secção social, solenemente, pronunciou, a 28 de fevereiro de 2002, 29 acórdãos "amianto".

\section{Amianto : obrigação de resultado e falta indesculpável}

Nos fundamentos de cada um desses acórdãos (Teissonnière \& Topaloff, 2002), a secção social do Suprema retoma o princípio de obrigação de segurança e de resultado : "em virtude do contrato de trabalho que o liga ao seu assalariado, o empregador tem para com este uma obrigação de segurança e de resultado, designadamente no que diz respeito às doenças profissionais contraídas pelo assalariado devido a produtos fabricados ou utilizados pela empresa". Depois de ter redefinido essa obrigação, essa jurisprudência reconhece a infração como falta indesculpável: "O não cumprimento desta obrigação, por parte do empregador, assume o carácter de falta indesculpável nos termos do artigo L.452-1 do Código da Segurança Social, quando o empregador tinha ou devia ter tido consciência do perigo a que o assalariado estava exposto e não tomou as medidas de prevenção necessárias para com ele".

10 Já não se trata, portanto, de qualificar uma "falta de extrema gravidade" (praticamente impossível de provar). A partir de 28 de fevereiro de 2002, a consciência do risco que o empregador tem ou deveria ter tido passou a ser o primeiro critério para se reconhecer uma falta indesculpável em matéria de doenças profissionais. Nos processos apresentados ao Supremo, os advogados puderam apoiar-se no conjunto de provas do conhecimento que as empresas francesas tinham desde a época longínqua em que se estabeleceu o princípio fundamental de obrigação de segurança e de resultado do empregador.

11 Com efeito, o amianto enquadra-se na categoria de "poeiras" nos termos da lei de 12 de junho de 1893 e dos decretos que definiam a aplicação das suas disposições, ainda incluídos no Código do Trabalho. No entanto, e mais precisamente, os primeiros indícios da toxicidade do amianto remontam, em França, a 1906, com a publicação de um artigo do inspetor do trabalho Denis Auribault, sobre as mortes ocorridas na fábrica Ferodo (uma filial da empresa inglesa Turner and Newal) na Normandia (Auribault, 1906). Posteriormente, vários artigos médicos publicados, nomeadamente de medicina do trabalho, chamam a atenção para as consequências do amianto na saúde (entre as décadas de 1930 e 1960). A referência ao amianto numa tabela de doenças profissionais 
remonta a 1946, antes da criação, em 1950, da tabela de DP nº 30, específica do amianto. Finalmente, os industriais franceses (e os médicos que colaboravam com eles para minimizar os riscos das fibras do amianto) participaram na "Conferência Internacional das Organizações de Informação sobre o Amianto" que se realizou em Londres em 1971, por iniciativa das empresas ligadas a esse setor, com o objetivo de atrasar, o mais possível, a divulgação dos conhecimentos sobre os perigos do amianto para a saúde que pudessem conduzir a regulamentações rigorosas (Thébaud-Mony, 2014, p. 61-62). As conclusões a que esses industriais chegaram, depois desta conferência, vão levar à criação, por iniciativa deles próprios, da Comissão Permanente do Amianto que vai assegurar a difusão do mito da "utilização controlada do amianto", do início da década de 1980 até à decisão da proibição do amianto em França, dezassete anos mais tarde.

Todos estes factos chamaram a atenção dos juízes e conduziram a uma evolução da jurisprudência em matéria de falta indesculpável do empregador, favorável não só à indemnização dos trabalhadores vítimas do amianto, mas também à prevenção com base no fundamento da "obrigação de segurança e de resultado". Assim que surgem as doenças causadas pelo amianto, a insuficiência e a desadequação das medidas tomadas pelo empregador, ou a ausência delas, provam o não cumprimento pelo empregador da obrigação que lhe incumbe.

\section{Uma estratégia judicial secundarizada devido à criação do Fundo de Indemnização das Vítimas do Amianto (FIVA)}

13 Esta decisão judicial surgiu em França, na altura em que a lei do financiamento da segurança social de 2000 criara o FIVA, entidade responsável pelo pagamento de uma indemnização mais elevada às vítimas profissionais e ambientais [5]. Esta iniciativa legislativa tinha sido apoiada politicamente pelo patronato para quem esse Fundo podia representar uma forma de separar as vítimas do amianto das outras vítimas laborais e de reduzir o potencial âmbito da falta indesculpável do empregador, cada vez mais reconhecida pelos tribunais de recurso, mesmo antes de uma decisão do Supremo. Uma parte do movimento social de defesa das vítimas do amianto tinha sido seduzida pela suposta rapidez dos processos de indemnização do FIVA, apesar de haver quem the fosse hostil e recusasse, como foi o caso das antigas operárias da AMISOL, "trocar a justiça por um cheque" (Thébaud-Mony, 2007, p. 69-70).

14 De facto, a contradição persiste desde 1898 com a aprovação da lei sobre acidentes de trabalho que reconhece o direito de indemnização às vítimas de acidentes de trabalho, independentemente da causa, o que tende a banalizar os riscos do trabalho em detrimento da necessidade de prevenção.

15 No entanto, a lei que cria o FIVA inclui um artigo que estabelece que o Fundo pode agir judicialmente em substituição da vítima de doença profissional causada pelo amianto para obter reconhecimento da falta indesculpável do empregador infrator [ $\left.{ }^{6}\right]$. Contudo, esta disposição tem sido pouco aplicada : em 2017, dos 338,7 milhões de euros pagos em indemnizações, o FIVA recuperou apenas 23,20 milhões em ações sub-rogatórias nos tribunais de segurança social. No entanto, $72 \%$ das pessoas indemnizadas são-no por doença profissional, o que leva a crer que o contencioso por falta indesculpável devia ser muito maior. Ao contrário das decisões judiciais como as de 28 de fevereiro de 2002, 
os relatórios do FIVA não revelam os nomes dos culpados e não permitem saber quais são as grandes empresas - como a ETERNIT, a ASCOMETAL ou os estaleiros navais cujos assalariados vítimas do amianto podiam ter alegado falta indesculpável do empregador, obrigando este a suportar os custos. Desta forma, as responsabilidades dos empregadores mantêm-se totalmente ocultas.

\section{Conclusão}

A maioria das vítimas do amianto recorreu ao FIVA encorajada por várias associações, médicos e caixas de seguros de doença. 0 efeito dos emblemáticos acórdãos de fevereiro de 2002 não se traduziu, portanto, num esperado contencioso maciço das vítimas laborais do amianto, o que, por seu lado, poderia ter sido um incentivo para vítimas de outros riscos do trabalho.

Quanto à prevenção no local de trabalho, pouco tem que ver com o teor do esquecido acórdão de 27 de novembro de 1884, sobre o qual Pierre Sargos, presidente da secção social do Supremo na altura dos acórdãos sobre o amianto, afirmou tratar-se do "acórdão mais importante alguma vez pronunciado por um tribunal de última instância em matéria de proteção da segurança dos trabalhadores e de denúncia dos danos causados por uma atitude exploradora em prejuizo da vida alheia" (Sargos, 2015, p. 2179).

Essa "atitude exploradora" de que fala Pierre Sargos está na origem do desastre sanitário do amianto, como de muitos outros semelhantes (pesticidas, radioatividade, desreguladores endócrinos, etc.).

Foi também essa mentalidade que gerou a crise que agora vivemos, estando a obrigação de "rentabilidade" dos hospitais na origem das graves carências sentidas nas últimas semanas no combate aos riscos de infeção pelo COVID-19. A ministra francesa do Trabalho, quando se referiu à necessidade de retomar a construção civil durante a epidemia de COVID-19, independentemente dos riscos, tomou publicamente posição contra os fundamentos do Código do Trabalho, já com 125 anos, ao declarar que a obrigação de segurança da entidade patronal é uma "obrigação de meios" e não de "resultados" [7]. Para que a mensagem fosse bem entendida pelos inspetores do trabalho propensos a serem rigorosos com os patrões relativamente às proteções individuais necessárias para os trabalhadores, a ministra suspendeu um deles, impedindo-o de cumprir a sua missão, por ter desrespeitado "de forma deliberada, grave e reiterada as instruções da autoridade central do sistema de inspeção do trabalho sobre as ações de inspeção durante a epidemia do COVID-19" [8].

Perante a dimensão dos desastres causados por essa "atitude exploradora", o que aconteceu em França com o amianto nas últimas décadas revela que as mobilizações associativas, sindicais e da sociedade civil são cada vez mais indispensáveis à defesa dos direitos fundamentais dos trabalhadores à saúde, à dignidade e à justiça. 


\section{BIBLIOGRAFIA}

Auribault, D. (1906). Note sur l'hygiène et la sécurité des ouvriers dans les filatures et tissage d'amiante, Bulletin de l'inspection du travail, 120-132.

BIT (1973). L'amiante, ses risques pour la santé et leur prévention. Réunion d'experts sur la sécurité dans l'utilisation de l'amiante. Genève : Bureau International du Travail, 11-18 décembre.

Collectif intersyndical Sécurité des Universités Jussieu (1977). Danger, Amiante! Paris : Maspero. Sargos, P. (2015). Hygiène et sécurité du travail : qui se souvient de Jean Thommes? La semaine juridique générale, 49, 21, 2179-2186.

Teissonnière, J. P. \& Topaloff, S. (2002). L'affaire de l'amiante. Semaine sociale Lamy, Supplément $\mathrm{n}^{\circ} 1082,32 \mathrm{p}$.

Thébaud-Mony, A. (2007) Travailler peut nuire gravement à votre santé. Paris : La Découverte.

Thébaud-Mony, A. (2014). La science asservie. Santé publique : les collusions mortifêres entre industriels et chercheurs. Paris : La Découverte.

\section{NOTAS}

1. A tradução dos textos é feita sem acordo ortográfico. A edição online contém as adaptações ao novo acordo ortográfico.

2. Jurisprudência conhecida por "Dame veuve Villa", de 15 de julho de 1941

3. "O empregador toma as medidas necessárias para garantir a segurança e proteger a saúde física e mental dos trabalhadores. (...)" (artigo L4121-1 do Code du travail).

4. Directiva 89/391/CEE do Conselho de 12 junho de 1989 sobre "a aplicação de medidas tendentes a promover a melhoria da segurança e da saúde dos trabalhadores no local de trabalho" (https://www.legifrance.gouv.fr/affichTexte.do? cidTexte=JORFTEXT000000333571\&categorieLien $=\mathrm{i}$ )

5. Artigo 53 da Loi $n^{\circ} 2000-1257$ de 23 dezembro de 2000 sobre o financiamento da segurança social para 2001.

6. "O fundo é sub-rogado, até ao limite dos montantes pagos, nos direitos que o autor detém contra a pessoa responsável pelo dano, bem como contra as pessoas ou organizações obrigadas, a qualquer título, a garantir uma indemnização total ou parcial nos limites do montante das prestações a cargo das referidas pessoas." (Loi n 2000-1257 de 23 dezembro de 2000).

7. Muriel Pénicaud: "A lei prevê que eles são responsáveis por criar meios de proteção", explicou no programa Le Grand Jury RTL/Figaro/LCI. E insistiu: "Não são responsáveis se alguém, mais tarde, vier a adoecer, mas são responsáveis pelos meios que empregaram".

8. https://www.asso-henri-pezerat.org/soutien-a-anthony-smith/ 


\section{AUTORES}

\section{ANNIE THÉBAUD-MONY}

INSERM/IRIS, Université Sorbonne Paris Nord, 74 rue marcel Cachin, 93017 - Bobigny-Cedex annie.mony@gmail.com 